\title{
Alcohol misuse and outpatient follow-up after hospital discharge: a retrospective cohort study
}

Bryan Borg ${ }^{1}$, Ivor S. Douglas 2,3 , Madelyne Hull ${ }^{2}$, Angela Keniston ${ }^{2}$, Marc Moss ${ }^{3}$ and Brendan J. Clark ${ }^{3,4^{*}}$ (D)

\begin{abstract}
Purpose: Patients with alcohol misuse are less likely to receive preventive health services but more likely to utilize emergency health services. However, the association between alcohol misuse and outpatient follow-up after hospitalization is unknown and may depend on whether a patient experiences a critical illness. We sought to determine whether alcohol misuse was associated with lower rates of outpatient follow-up after hospital discharge and whether the magnitude of this association differed in patients who experienced a critical illness.
\end{abstract}

Materials and methods: This was a retrospective cohort study using administrative data from an urban safety net hospital. Patients were included if they were admitted between 2011 and 2015, were between the ages of 18 and 89, resided within the safety net county, were discharged home, and were at moderate to high risk for hospital readmission within the subsequent 30 days. Alcohol misuse was identified using a combination of ICD-9 codes and response to a single screening question. The primary outcome was a combined measure of follow-up with a primary care physician or specialist provider in the 30 days following hospital discharge. Multivariable logistic regression was used to adjust for factors known to be associated with healthcare utilization.

Results: Overall, 17,575 patients were included in the analysis; 4984 (28\%) had alcohol misuse. In the 30 days following hospital discharge, $46 \%$ of patients saw any outpatient provider. In an unadjusted analysis, the association between alcohol misuse and attending any outpatient follow-up was dependent on whether patients had a critical illness ( $p$ value $<0.0001$ ) with the highest rates of follow-up in survivors of critical illness without alcohol misuse $(53 \%$, 95\% Cl 51\%, 55\%) followed by patients without alcohol misuse or critical illness (49\%; 95\% Cl 48\%, 50\%), patients with alcohol misuse without critical illness (38\%; 95\% Cl 36\%, 39\%), and patients with alcohol misuse and a critical illness (37\%; 95\% Cl 35\%, 40\%). Adjusting for factors associated with healthcare utilization, these findings were modestly attenuated but unchanged.

Conclusions: Patients with alcohol misuse who are at moderate to high risk for hospital readmission may benefit from targeted interventions to increase rates of outpatient follow-up after hospital discharge.

Keywords: Alcohol abuse, Alcoholism, Alcohol use disorder, Alcohol dependence, Hospital readmission, Healthcare utilization, Intensive care unit

\footnotetext{
*Correspondence: brendan.clark@ucdenver.edu

${ }^{3}$ Division of Pulmonary Sciences and Critical Care Medicine, Department of Medicine, University of Colorado Anschutz Medical Campus, Box C272, RC2, 9th Floor, 12700 East 19th Avenue, Aurora, CO 80045, USA

Full list of author information is available at the end of the article
} 


\section{Introduction}

The spectrum ranging from excessive alcohol use without consequences to the presence of an alcohol use disorder (AUD) is referred to as alcohol misuse [1]. Alcohol misuse predisposes to and can increase the severity of numerous conditions that may require hospitalization including community acquired pneumonia, trauma, gastrointestinal bleeding, sepsis, alcohol withdrawal, and acute respiratory failure [2-5]. Consequently, up to onethird of hospitalized patients have alcohol misuse; most hospitalized patients with alcohol misuse have alcohol misuse [6-12]. Following hospital discharge, patients with alcohol misuse have significantly higher rates of hospital readmission within 30 days [13, 14].

The hospital discharge process is complex and a vulnerable time for patients. Up to $20 \%$ of Medicare patients will be readmitted to the hospital within 30 days [15]. Because some of these hospital readmissions are avoidable and add unnecessary cost, there has been an intense effort to reduce rates of hospital readmission. Interventions designed to reduce rates of hospital readmission are often multifaceted [16]. In the pre-discharge time period, these interventions may include patient education, discharge planning, and medication reconciliation [17-19]. Common post-discharge interventions may include a follow-up telephone call, a discharge hotline, and communication with the outpatient provider [17-19]. In addition, some experts argue that multi-faceted interventions would be most effective if they bridged to timely outpatient follow-up [18]. Although there is scant data from randomized controlled trials to support this assertion, several observational studies demonstrate a reduction in hospital readmission for patients who attend follow-up appointments, particularly among patients at high risk for hospital readmission [20-22]. Therefore, identifying groups that are at high risk for not following up with their outpatient providers may identify a group where targeted interventions could improve outcomes.

Prior studies have demonstrated that patients with alcohol misuse over-utilize unplanned emergency services such as emergency department visits and hospital or intensive care unit (ICU) admissions and under-utilize planned, primary care and preventive services such as cancer screening and health maintenance [23-28]. Despite this understanding, there have been no studies focusing on the relationship between alcohol misuse and outpatient follow-up after hospital discharge.

Patterns of healthcare utilization also vary based on whether a patient requires care in an ICU during their hospitalization. Patients may require care in an ICU because of a severe, life-threatening illness that requires additional levels of support or a higher level of monitoring. Following hospital discharge, ICU survivors frequently face a constellation of new or worsening mental and physical health problems including symptoms of anxiety, depression, post-traumatic stress disorder, and loss of physical function [29-33]. Perhaps because of this constellation of new physical and mental health problems, survivors of critical illness have higher rates of healthcare utilization after hospital discharge [34]. It is possible that these higher rates of healthcare utilization in ICU survivors could be attenuated by ongoing alcohol misuse.

Given the high prevalence of alcohol misuse in hospitalized patients, its association with increased morbidity and mortality following hospital discharge, and the known association between outpatient follow-up and improved outcomes, we sought to determine whether alcohol misuse was associated with lower rates of outpatient follow-up after hospital discharge. Furthermore, because survivors of critical illness have higher rates of healthcare utilization, we sought to determine whether the magnitude of this association depended on whether a patient received care in an ICU.

\section{Materials and methods \\ Study design, setting, and data sources}

This was a retrospective cohort study which utilized existing data from patients who received care at a Denver Health clinic or at Denver Health Medical Center. Denver Health is a safety net health system that provides care to $25 \%$ of all Denver residents, around 150,000 individuals. In the United States, a safety net hospital is one that provides healthcare to patients regardless of their ability to pay. Denver Health also provides training for medical professionals. The population served includes numerous patients who are uninsured, homeless, have psychiatric illness, or drug or alcohol use disorders. Data for admissions were extracted through the Denver Health Data Warehouse, including prescribing, billing, and outcomes data for the 3 years preceding each admission and 30 days following hospital discharge. The Denver Health Data Warehouse contains data for visits at any Denver Health outpatient clinic as well as data from inpatient stays at Denver Health Hospital.

\section{Study sample}

The study sample included patients age $\geq 18$ years and $\leq 89$ years who were discharged home from Denver Health Hospital after admission from the emergency department or adult urgent care clinic between 1/2011 and $12 / 2015$, resided in Denver County and had a moderate to high risk of hospital readmission within 30 days based on their length of stay in hospital $[\mathrm{L}]$, acuity of admission $[\mathrm{A}]$, comorbidity $[\mathrm{C}]$ and emergency department utilization in the 6 months before admission 
[E] (LACE + Index). The LACE + Index is a validated model with good discrimination to predict the risk of unplanned readmission or death within 30 days of hospital discharge. A score $\geq 29$ suggests at least moderate risk of readmission [35]. A recent review comparing the effectiveness of various 30-readmission risk calculators including the LACE + index found no significant difference in performance between these tools when applied to a large cohort [36]. The LACE + index can be calculated automatically by the electronic records system used at Denver Health. Patients who were admitted to correctional care, psychiatric care, labor and delivery services or were discharged to skilled nursing facilities, long term acute care hospitals, hospice care, or who died in-hospital were excluded. When a patient had multiple admissions during the study period, only the first admission was considered. This study received approval including a waiver of informed consent and Health Insurance Portability and Accountability Act authorization from the Colorado Multiple Institutional Review Board.

\section{Outcomes}

The appropriate venue for follow-up after hospital discharge could include either primary care or specialty care. Therefore, the primary outcome variable was attendance at either within 30 days of hospital discharge [20]. Secondary outcomes included attendance at an outpatient primary care appointment or attendance at an outpatient specialty care appointment considered separately.

\section{Independent variable}

The independent variable of interest was an interaction term between alcohol misuse and critical illness. A priori, we planned to examine the association between alcohol misuse and outpatient follow-up independent of critical illness only if this interaction term was not significant [37]. Patients with International Classification of Diseases (ICD) codes consistent with an alcohol use disorder (ICD-9 prefix 291 or 303, ICD 10 prefix F10.1, F10.2, or F10.9) [38] in the preceding 3 years were considered to have alcohol misuse. In addition, patients who responded yes to the single screening question for alcohol misuse, "In the past 3 months, have you had more than 4 (all women and men $>65)$ or $5($ Men $<65)$ alcoholic beverages in 1 day?" were considered to have alcohol misuse. We chose to include screening results in the definition of alcohol misuse because of the limited sensitivity of alcohol codes in administrative data [38]. This question has a sensitivity of $83 \%$ and specificity of $72 \%$ for past year alcohol use disorder and sensitivity of $86 \%$ and specificity of $86 \%$ for alcohol misuse [39]. Patients who were admitted to an ICU for any part of their hospital stay were considered to have a critical illness.

\section{Covariates}

Pre-specified co-variates were selected because of their association with health care utilization and included age (continuous), gender, race/ethnicity (White, Black, Hispanic, Other), payer source (Commercial, Self-Pay, Medicare, Medicaid), homelessness and medical co-morbidities measured using the Charlson/Deyo index [40]. As previously described, the Charlson/Deyo index was considered as a categorical variable [41].

\section{Statistical analysis}

Differences between patients with and without alcohol misuse were compared using $t$ tests for normally distributed continuous variables and Chi square tests for categorical variables. To determine whether the association between alcohol misuse and outpatient follow-up was dependent on whether a patient experienced a critical illness, we used the Cochran-Mantel-Haenszel test in unadjusted analyses and an interaction term between alcohol misuse and ICU stay in multivariable analyses. Three separate multivariable logistic regression models were utilized with an interaction between alcohol misuse and critical illness as the predictor variable and any outpatient follow-up, follow-up with a primary care provider, and follow-up with a specialist provider as separate outcomes. Each multivariable analysis was adjusted for the previously outlined pre-specified covariates and included the main effects for alcohol misuse and critical illness. For the analyses using any outpatient follow-up and specialist follow-up as the outcome variable, interaction terms were significant. Therefore, results are displayed by subgroups stratified by alcohol misuse and critical illness. For the analysis using follow-up with a primary care provider as the outcome variable, the interaction term was not significant. Therefore, we present alcohol misuse and critical illness as main effects.

\section{Results}

Of the 37,763 admissions during the study period who met inclusion criteria, 17,575 were included in this analysis (Fig. 1). Among patients included in the study sample, $28 \%$ had alcohol misuse. The average age of the sample was 56.7 years and $58 \%$ were male (Table 1). Most patients were white, non-Hispanic (43\%) or Hispanic (37\%). Almost a quarter of the entire sample was homeless and $16 \%$ had a substance use disorder other than alcohol. Patients with alcohol misuse were significantly more likely to be younger, male, homeless, have a concomitant substance use disorder, mental health 
37,763 Admissions Screened for Study

1) Inpatient discharge after admission from the Denver Health ED or Urgent Care from 1/2011-12/2015.

2) Ages $18-89$

3) Residence within Denver County

4) LACE + Index $\geq 29$, indicative of moderate to high risk of readmission

5) Not Correctional, Labor and Delivery, or psychiatric admission

6) Not discharged to LTACH, SNF, hospice, or death in hospital.

20,188 Multiple, non-unique patient encounters excluded

Fig. 1 Selection of study sample

Table 1 Baseline characteristics

\begin{tabular}{|c|c|c|c|c|}
\hline & $\begin{array}{l}\text { Overall } \\
N=17,575\end{array}$ & $\begin{array}{l}\text { Alcohol misuse } \\
\mathrm{N}=4984\end{array}$ & $\begin{array}{l}\text { No alcohol misuse } \\
\mathrm{N}=12,591\end{array}$ & p value \\
\hline Age (mean) & 56.7 & 53.8 & 57.9 & $<0.0001$ \\
\hline Male gender (\%) & 57.8 & 68.8 & 53.5 & $<0.0001$ \\
\hline Ethnicity & & & & $<0.0001$ \\
\hline White (\%) & 42.7 & 46.7 & 41.1 & \\
\hline Black (\%) & 16.4 & 15.8 & 16.6 & \\
\hline Hispanic (\%) & 36.8 & 33.3 & 38.1 & \\
\hline Other (\%) & 4.2 & 4.2 & 4.2 & \\
\hline Homelessness (\%) & 23.2 & 34.7 & 18.7 & $<0.0001$ \\
\hline \multicolumn{5}{|l|}{ Comorbidities } \\
\hline Other substance use disorder (\%) & 16.2 & 24.7 & 12.5 & $<0.0001$ \\
\hline Bipolar disorder (\%) & 9.2 & 11.4 & 7.2 & $<0.0001$ \\
\hline Depression (\%) & 30.4 & 33.4 & 29.1 & $<0.0001$ \\
\hline Schizophrenia (\%) & 4.4 & 5.5 & 3.9 & $<0.0001$ \\
\hline Hepatitis C (\%) & 11.5 & 17.4 & 8.9 & $<0.0001$ \\
\hline HIV/AIDS (\%) & 2.9 & 3.7 & 2.5 & $<0.0001$ \\
\hline Mild liver disease (no portal hypertension) (\%) & 5.2 & 9.9 & 3.1 & $<0.0001$ \\
\hline Moderate-severe liver disease (\%) & 2.9 & 5.9 & 1.5 & $<0.0001$ \\
\hline Payer source & & & & $<0.0001$ \\
\hline Self pay/other (\%) & 26.2 & 32.3 & 23.8 & \\
\hline Medicaid (\%) & 32.5 & 35.3 & 31.5 & \\
\hline Medicare (\%) & 32.9 & 25.2 & 36.0 & \\
\hline Commercial (\%) & 8.3 & 7.2 & 8.8 & \\
\hline Charlson/Deyo index & & & & $<0.0001$ \\
\hline $0(\%)$ & 5.6 & 8.7 & 4.3 & \\
\hline $1-2(\%)$ & 45.7 & 51.0 & 43.6 & \\
\hline$\geq 3(\%)$ & 48.7 & 40.3 & 52.1 & \\
\hline Length of stay (days) & 4.1 & 4.4 & 4.0 & $<0.01$ \\
\hline
\end{tabular}

AIDS acquired immunodeficiency syndrome, HIV human immunodeficiency virus, Charlson/Deyo index a measure of medical comorbidities 
comorbidities, and liver disease, but lower median Charlson-Deyo Comorbidity score.

In the 30 days following hospital discharge, $46 \%$ of patients saw any outpatient provider, $34 \%$ saw a primary care provider, $23 \%$ saw a specialty provider, and $11 \%$ saw both types of providers. Males, patients who were homeless, and patients with substance use and mental health disorders had significantly lower rates of outpatient follow-up. In unadjusted analyses, the associations between alcohol misuse and attending any outpatient follow-up as well follow-up with a primary care provider or a specialist were all dependent on whether patients had a critical illness (Cochran-Mantel-Haenszel p value $<0.0001$ ). Patients with alcohol misuse who experienced a critical illness had the lowest rates of any outpatient follow-up and primary care physician follow-up (Table 2). In contrast, survivors of critical illness without alcohol misuse had significantly higher rates of outpatient follow-up when compared to patients without alcohol misuse who did not have a critical illness $(\mathrm{p}<0.001)$. The high rates of outpatient follow-up for this group were driven by both higher rates of follow-up with a primary care provider and a specialist.

Adjusted for age, gender, race/ethnicity, payer source, medical comorbidities, and homelessness, the association between alcohol misuse and any outpatient followup remained dependent on whether a patient had been admitted to an ICU during their hospital stay ( $\mathrm{p}$ value for interaction term $<0.01$ ). Among the 4103 patients admitted to an ICU, the odds of outpatient follow-up were significantly lower in patients with alcohol misuse when compared to those without (OR 0.60; 95\% CI 0.52, 0.70) (Table 3). Among the 13,472 patients who were not admitted to an ICU during their hospital stay, patients with alcohol misuse were also less likely to attend any outpatient follow-up though the association was not as strong (OR 0.76; 95\% CI 0.70, 0.83).

Similarly, after adjusting for age, gender, race/ethnicity, payer source, medical comorbidities, and homelessness, the association between alcohol misuse and specialist follow-up remained dependent on whether patients had been admitted to an ICU ( $p$ value for interaction $=0.004$ ). Among patients admitted to an ICU during their hospital stay, the odds of follow-up with a specialist provider were significantly lower in patients with alcohol misuse when compared to those without (OR 0.55; 95\% CI 0.47, 0.64) (Table 3). Among the patients who were not admitted to an ICU during their hospital stay, patients with alcohol misuse had significantly lower odds of outpatient followup with a specialist provider (OR 0.69; 95\% CI 0.62, 0.76) (Table 4).

In a fully adjusted analysis, the relationship between alcohol misuse and follow-up with a primary care physician was not dependent on whether a patient experienced a critical illness. However, patients with alcohol misuse (OR 0.85; 95\% CI 0.79, 0.92) and survivors of critical illness (OR 0.87; 95\% CI 0.81, 0.95) were significantly less likely to see a primary care physician (Table 5 ).

A key assumption in this analysis was that access to care was equal across groups. To test this assumption, we conducted a sensitivity analysis in the subset of patients who had seen a primary care provider within the system in the 3 years preceding the index admission. The inferences were unchanged. The adjusted odds of outpatient follow-up with any provider and the odds of follow-up with a primary care provider were lower than those seen in the overall cohort (Additional file 1: Table S1).

\section{Discussion}

In this retrospective cohort study of over 17,000 patients who received care in a single metropoli$\tan$ health network, we sought to determine whether patients with alcohol misuse were less likely to attend outpatient follow-up visits after hospitalization for a medical illness. We found that, overall, less than half of patients at moderate to high risk of hospital readmission saw any outpatient provider in the 30 days after hospital discharge. However, patients who experienced

Table 2 Unadjusted rates of outpatient follow-up within $\mathbf{3 0}$ days of hospital discharge

\begin{tabular}{|c|c|c|c|c|c|c|}
\hline & \multicolumn{2}{|c|}{ Any outpatient provider* } & \multicolumn{2}{|c|}{ Primary care physician* } & \multicolumn{2}{|c|}{ Specialist physician* } \\
\hline & $\%, 95 \% \mathrm{Cl}$ & $p$ value & $\%, 95 \% \mathrm{Cl}$ & p value & $\%, 95 \% \mathrm{Cl}$ & p value \\
\hline \multicolumn{7}{|l|}{ Critical illness } \\
\hline No alcohol misuse $(n=2840)$ & $53(51,55)$ & Ref & $31(29,33)$ & Ref & $35(34,37)$ & Ref \\
\hline Alcohol misuse $(n=1263)$ & $37(35,40)$ & $<0.001$ & $24(22,27)$ & $<0.001$ & $22(20,24)$ & $<0.001$ \\
\hline \multicolumn{7}{|l|}{ No critical illness } \\
\hline No alcohol misuse $(n=9751)$ & $49(48,50)$ & Ref & $37(36,38)$ & Ref & $23(22,23)$ & Ref \\
\hline Alcohol misuse $(n=3721)$ & $38(36,39)$ & $<0.001$ & $29(27,30)$ & $<0.001$ & $16(15,17)$ & $<0.001$ \\
\hline
\end{tabular}

**Cochran-Mantel-Haenszel $p$ value $<0.0001$ when stratifying relationship between alcohol misuse and outcome by critical illness 
Table 3 Unadjusted and adjusted association between alcohol misuse and any outpatient follow-up as well as follow-up with a specialist provider in the $\mathbf{3 0}$ days following hospital discharge among patients who were admitted to an intensive care unit during their hospital stay

\begin{tabular}{|c|c|c|c|c|}
\hline & \multicolumn{2}{|c|}{ Any outpatient follow-up $(n=4103)$} & \multicolumn{2}{|c|}{ Specialist provider $(n=4103)$} \\
\hline & Unadjusted OR (95\% Cl) & Adjusted OR (95\% CI) & Unadjusted OR (95\% Cl) & Adjusted OR (95\% Cl) \\
\hline Alcohol misuse & $0.54(0.47,0.61)^{z}$ & $0.60(0.52,0.70)^{z}$ & $0.66(0.60,0.73)^{Z}$ & $0.55(0.47,0.64)^{\mathrm{Z}}$ \\
\hline Age & & $1.01(1.00,1.02)^{* *}$ & & $1.00(1.00,1.01)$ \\
\hline Gender (male) & & $0.81(0.71,0.93)^{* *}$ & & $1.18(1.02,1.37)^{* *}$ \\
\hline \multicolumn{5}{|l|}{ Race } \\
\hline White, non-hisp & & Ref & & Ref \\
\hline Black & & $1.33(1.0,1.61)^{* *}$ & & $1.05(0.85,1.30)$ \\
\hline Hispanic & & $1.79(1.55,2.07)^{\mathrm{Z}}$ & & $1.29(1.11,1.50)^{*}$ \\
\hline Other & & $1.29(0.93,1.78)$ & & $1.36(0.97,1.90)$ \\
\hline \multicolumn{5}{|l|}{ Payer source } \\
\hline Commercial & & Ref & & Ref \\
\hline Medicaid & & $1.27(1.02,1.59)^{* *}$ & & $0.82(0.65,1.03)$ \\
\hline Medicare & & $0.75(0.60,0.96)^{* *}$ & & $0.54(0.42,0.69)^{z}$ \\
\hline Self-pay/other & & $0.97(0.77,1.22)$ & & $0.78(0.62,0.99)^{* *}$ \\
\hline Homeless & & $0.56(0.48,0.66)^{\mathrm{Z}}$ & & $0.53(0.44,0.64)^{Z}$ \\
\hline \multicolumn{5}{|l|}{ Charlson/Deyo } \\
\hline 0 & & Ref & & Ref \\
\hline $1-2$ & & $1.02(0.79,1.30)$ & & $0.79(0.61,1.02)$ \\
\hline$\geq 3$ & & $1.26(0.96,1.65)$ & & $1.05(0.79,1.40)$ \\
\hline
\end{tabular}

Charlson/Deyo index is a measure of medical comorbidities

OR odds ratio

z $\mathrm{p}<0.0001 ;{ }^{*}<0.001 ;{ }^{* *}<0.05$

a critical illness without alcohol misuse had significantly higher rates of follow-up. Conversely, patients with alcohol misuse consistently had lower rates of outpatient follow-up regardless of whether they experienced a critical illness. It is possible that we did not observe higher rates of follow-up in ICU survivors with alcohol misuse because they do not differentially decrease their alcohol consumption when compared to patients with alcohol misuse who were not admitted to an ICU.

These findings have several potential limitations. First, by defining alcohol misuse using ICD-9 codes or a positive response to a single screening question, we may be combining patients with at-risk alcohol use and those with an alcohol use disorder. Prior work in a similar setting (an urban safety net hospital) demonstrated that $77 \%$ of medical inpatients enrolled in a study of brief intervention for alcohol misuse had DSM-IV alcohol dependence [42]. Therefore, even with the limitations of our definition of alcohol misuse, it is very likely that many patients that we identified as having alcohol misuse had an AUD. Unfortunately, within the patients we identify as having alcohol misuse, there is no reliable way to determine which had at-risk use and which had an AUD.
Second, it is probable that rates of outpatient follow-up were underestimated since we were only able to account for follow-up within the Denver Health system. However, it is unlikely that this occurred differentially between patients with and without alcohol misuse. Third, we did not account for post-discharge out-of-hospital death in our analysis. Death is a competing risk for outpatient follow-up. However, patients with alcohol misuse have a higher risk of death following hospital discharge so it is likely that this would lead to an underestimation of the true effect size [43]. Fourth, although we based our primary inference on a statistical analysis that accounted for differences in socioeconomic status and our findings persisted in a subgroup of patients with known access to outpatient care, there is the possibility that our findings are due to residual or unmeasured confounding. Fifth, because this study used administrative data, it is possible that some follow-up visits were unrelated to the hospitalization and, thus, do not reflect a continuum of care. Furthermore, with the available data, we were unable to distinguish whether an appointment was made and not kept or never made at all. Finally, this study was conducted using a sample that receives care at a safety net hospital. Patients in this sample are generally of lower 
Table 4 Unadjusted and adjusted association between alcohol misuse and any outpatient follow-up as well as follow-up with a specialist provider in the $\mathbf{3 0}$ days following hospital discharge among patients who were not admitted to an intensive care unit during their hospital stay

\begin{tabular}{|c|c|c|c|c|}
\hline & \multicolumn{2}{|c|}{ Any outpatient follow-up $(n=13,472)$} & \multicolumn{2}{|c|}{ Specialist provider $(n=13,472)$} \\
\hline & Unadjusted OR (95\% Cl) & Adjusted OR $(95 \% \mathrm{Cl})$ & Unadjusted OR (95\% CI) & Adjusted OR $(95 \% \mathrm{Cl})$ \\
\hline Alcohol misuse & $0.64(0.59,0.69)^{Z}$ & $0.76(0.70,0.83)^{z}$ & $0.66(0.60,0.73)^{z}$ & $0.69(0.62,0.76)^{z}$ \\
\hline Age & & $1.00(0.99,1.00)$ & & $0.98(0.98,0.99)^{Z}$ \\
\hline Gender (male) & & $0.67(0.63,0.72)^{Z}$ & & $0.95(0.87,1.03)$ \\
\hline \multicolumn{5}{|l|}{ Race } \\
\hline White, non-Hispanic & & Ref & & Ref \\
\hline Black & & $1.61(1.46,1.79)^{\mathrm{Z}}$ & & $1.19(1.06,1.35)^{* *}$ \\
\hline Hispanic & & $1.97(1.82,2.14)^{Z}$ & & $1.1 .33(1.21,1.47)^{\mathrm{Z}}$ \\
\hline Other & & $1.10(0.91,1.31)$ & & $1.12(0.90,1.40)$ \\
\hline \multicolumn{5}{|l|}{ Payer source } \\
\hline Commercial & & Ref & & Ref \\
\hline Medicaid & & $1.85(1.59,2.16)^{\mathrm{Z}}$ & & $1.19(0.99,1.42)$ \\
\hline Medicare & & $1.53(1.31,1.78)^{\mathrm{Z}}$ & & $0.97(0.80,1.17)$ \\
\hline Self-pay/other & & $1.25(1.07,1.46)^{\mathrm{Z}}$ & & $1.02(0.85,1.23)$ \\
\hline Homeless & & $0.62(0.57,0.68)^{Z}$ & & $0.68(0.61,0.76)^{Z}$ \\
\hline \multicolumn{5}{|l|}{ Charlson/Deyo } \\
\hline 0 & & Ref & & Ref \\
\hline $1-2$ & & $0.99(0.83,1.19)$ & & $0.74(0.61,0.91)^{* *}$ \\
\hline$\geq 3$ & & $1.40(1.16,1.70)^{*}$ & & $1.13(0.79,1.40)$ \\
\hline
\end{tabular}

Charlson/Deyo index is a measure of medical comorbidities

OR odds ratio

z $\mathrm{p}<0.0001 ;{ }^{*}<0.001 ;{ }^{* *}<0.05$

socioeconomic status. Therefore, these findings may not apply to other hospital systems.

The lower rates of outpatient follow-up after hospital discharge among patients with alcohol misuse are consistent with prior studies demonstrating that patients with alcohol misuse are less likely to receive preventive health care [44]. One potential explanation for the lower rates of follow-up among patients with alcohol misuse could be that patients who are actively intoxicated are less likely to receive care. Alternatively, patients with alcohol misuse may actively avoid interactions with healthcare providers because of shame, because they feel embarrassed, because they did not want to engage in discussions about their drinking, or because drinking may have a higher priority in their life [45].

Finally, it is possible that patients and/or providers perceive that there is no need for outpatient follow-up. For example, patients and providers may perceive that an illness is solely related to alcohol, agree that the plan should be to cut down or stop drinking, and, therefore, decide that no additional follow-up is indicated. This may lead to a missed opportunity for patients with alcohol misuse for several reasons. Given the high rate of AUDs among these hospitalized patients, there may be the opportunity to effectively manage AUDs in the primary care setting. Though data on this is conflicting, some clinical trials demonstrate effectiveness [46-48]. For patients with atrisk use, follow-up with a primary care physician would offer an opportunity re-evaluate drinking, thus delivering a multi-contact intervention. These brief multi-contact interventions have the strongest evidence base [49]. Second, many patients who are hospitalized for an illness may need chronic medications to manage their condition. Examples of this include patients with congestive heart failure or chronic obstructive pulmonary disease. Given prior data that demonstrates higher rates of medication non-adherence among patients with alcohol misuse, outpatient follow-up may provide an opportunity to identify and overcome barriers to adherence [50].

Our findings suggest that it may be important to tailor interventions to increase outpatient follow-up following hospital discharge for patients with alcohol misuse. Previously described interventions to increase rates of outpatient follow-up after hospital discharge do not account for potentially unique barriers such as shame, embarrassment, stigma, difficulties building therapeutic alliance, and psychiatric comorbidities that may prevent patients with alcohol misuse from 
Table 5 The relationship between alcohol misuse and follow-up with a primary care physician did not depend on whether a patient had a critical illness

\begin{tabular}{|c|c|c|}
\hline & \multicolumn{2}{|l|}{ Primary care physician } \\
\hline & Unadjusted OR ( $95 \% \mathrm{Cl})$ & Adjusted OR (95\% Cl) \\
\hline No alcohol misuse & Ref & Ref \\
\hline Alcohol misuse & $0.69(0.64,0.74)^{\mathrm{Z}}$ & $0.85(0.79,0.92)^{Z}$ \\
\hline No critical illness & Ref & Ref \\
\hline Critical illness & $0.77(0.71,0.83)^{Z}$ & $0.87(0.81,0.95)^{Z}$ \\
\hline Age & & $1.01(1.00,1.01)^{\mathrm{Z}}$ \\
\hline Gender (male) & & $0.63(0.0 .59,0.68)^{z}$ \\
\hline \multicolumn{3}{|l|}{ Race } \\
\hline White, non-hisp & & Ref \\
\hline Black & & $1.65(1.50,1.82)^{\mathrm{Z}}$ \\
\hline Hispanic & & $2.07(1.92,2.23)^{Z}$ \\
\hline Other & & $1.11(0.94,1.32)^{\mathrm{a}}$ \\
\hline \multicolumn{3}{|l|}{ Payer source } \\
\hline Commercial & & Ref \\
\hline Medicaid & & $2.18(1.89,2.52)^{Z}$ \\
\hline Medicare & & $1.84(1.59,2.13)^{Z}$ \\
\hline Self-pay/other & & $1.28(1.10,1.49)$ \\
\hline Homeless & & $0.72(0.66,0.78)^{\mathrm{Z}}$ \\
\hline \multicolumn{3}{|l|}{ Charlson/Deyo } \\
\hline 0 & & Ref \\
\hline $1-2$ & & $1.53(1.28,1.83)$ \\
\hline$\geq 3$ & & $1.93(1.60,2.34)^{z}$ \\
\hline
\end{tabular}

Charlson/Deyo index is a measure of medical comorbidities

$O R$ odds ratio

${ }^{z} \mathrm{p}<0.0001 ;{ }^{*}<0.001 ;{ }^{* *}<0.05$

following up with outpatient providers [51-53]. Tailoring a care transition intervention to patients with alcohol misuse could lead to improved outcomes at a lower cost, thus improving the value of care. While the optimal method for linking patients with alcohol misuse to care outside of the inpatient setting is unclear, promising approaches include the use of incentives, introducing the patient to the clinician who they will see after hospital discharge, and providing an escort to the patient's first appointment [54-57].

The finding that survivors of critical illness with alcohol misuse have the lowest rates of outpatient follow-up is concerning. When compared to survivors of critical illness without alcohol misuse, survivors of critical illness with alcohol misuse have a higher risk of morbidity and mortality following hospital discharge [14]. This higher risk of morbidity and mortality is likely driven by a combination of new or worsening chronic health problems and underlying mental health problems [58]. Given the higher risk of poor outcomes in this population, rates of outpatient follow-up among survivors of critical illness with alcohol misuse should be comparable or higher than those without alcohol misuse.

\section{Conclusions}

This study demonstrates that patients with alcohol misuse who are at moderate to high risk for hospital readmission have lower rates of follow-up within 30 days of hospital discharge. Rates of follow-up for survivors of critical illness with alcohol misuse, a group known to be at higher risk for morbidity and mortality, were disappointingly low. Ongoing efforts to improve the bridge to outpatient longitudinal care for patients with alcohol misuse could reduce readmissions, decrease healthcare costs, and improve outcomes.

\section{Additional file}

Additional file 1: Table S1. Unadjusted and multivariable analyses within population that had seen any Primary Care clinic in preceding 3 years examining the association between alcohol misuse and any outpatient follow-up, follow-up with a primary care provider, and follow-up with a specialist.

\section{Abbreviations}

AUD: alcohol use disorder; ICU: intensive care unit; LACE: length of stay, acuity comorbidity, emergency department utilization; HIPAA: Health Insurance Portability and Accountability Act; ICD: International Classification of Diseases.

\section{Authors' contributions}

$\mathrm{BB}, \mathrm{ISD}, \mathrm{MH}, \mathrm{AK}, \mathrm{MM}$ and $\mathrm{BJC}$ contributed to the study design, acquisition of data, analysis and interpretation of data, were involved in drafting the manuscript, have approved the final version of manuscript, and agree to be accountable for all aspects of the work. All authors read and approved the final manuscript.

\section{Author details}

${ }^{1}$ Department of Medicine, University of Colorado Anschutz Medical Campus, Aurora, CO, USA. ${ }^{2}$ Denver Health Medical Center, Denver, CO, USA. ${ }^{3}$ Division of Pulmonary Sciences and Critical Care Medicine, Department of Medicine, University of Colorado Anschutz Medical Campus, Box C272, RC2, 9th Floor, 12700 East 19th Avenue, Aurora, CO 80045, USA. ${ }^{4}$ Division of Substance Dependence, University of Colorado Anschutz Medical Campus, Aurora, CO, USA.

\section{Acknowledgements}

This study was approved by the Colorado Multiple Institutional Review Board, including a waiver of informed consent (COMIRB \# 15-1280). This work was supported by the National Institutes of Health (K23 AA 021814, BJC). The data that support the findings of this study are available from Denver Health but restrictions apply to the availability of these data, which were used under license for the current study, and so are not publicly available. Data are however available from the authors upon reasonable request and with permission of Denver health.

\section{Competing interests}

The authors declare that they have no competing interests.

\section{Publisher's Note}

Springer Nature remains neutral with regard to jurisdictional claims in published maps and institutional affiliations. 
Received: 15 November 2017 Accepted: 29 November 2018 Published online: 04 December 2018

\section{References}

1. Saitz R. Clinical practice. Unhealthy alcohol use. N Engl J Med. 2005;352:596-607.

2. O'Brien JM Jr, Lu B, Ali NA, Martin GS, Aberegg SK, Marsh CB, Lemeshow S, Douglas IS. Alcohol dependence is independently associated with sepsis, septic shock, and hospital mortality among adult intensive care unit patients. Crit Care Med. 2007;35:345-50.

3. Fernandez-Sola J, Junque A, Estruch R, Monforte R, Torres A, UrbanoMarquez A. High alcohol intake as a risk and prognostic factor for community-acquired pneumonia. Arch Intern Med. 1995;155:1649-54.

4. de Wit M, Best AM, Gennings C, Burnham EL, Moss M. Alcohol use disorders increase the risk for mechanical ventilation in medical patients. Alcohol Clin Exp Res. 2007;31:1224-30.

5. Borges G, Cherpitel CJ, Orozco R, Bond J, Ye Y, Macdonald S, Giesbrecht N, Stockwell T, Cremonte M, Moskalewicz J, et al. Acute alcohol use and the risk of non-fatal injury in sixteen countries. Addiction. 2006;101:993-1002.

6. Dawson NV, Dadheech G, Speroff T, Smith RL, Schubert DS. The effect of patient gender on the prevalence and recognition of alcoholism on a general medicine inpatient service. J Gen Intern Med. 1992;7:38-45.

7. Deehan A, Marshall EJ, Strang J. Tackling alcohol misuse: opportunities and obstacles in primary care. Br J Gen Pract. 1998;48:1779-82.

8. Dolman JM, Hawkes ND. Combining the audit questionnaire and biochemical markers to assess alcohol use and risk of alcohol withdrawal in medical inpatients. Alcohol Alcohol. 2005;40:515-9.

9. Gerke P, Hapke U, Rumpf HJ, John U. Alcohol-related diseases in general hospital patients. Alcohol Alcohol. 1997;32:179-84.

10. Moore RD, Bone LR, Geller G, Mamon JA, Stokes EJ, Levine DM. Prevalence, detection, and treatment of alcoholism in hospitalized patients. JAMA. 1989;261:403-7.

11. Reisinger MW, Moss M, Clark BJ, National Heart L. Blood institute acute respiratory distress syndrome network I: brief versus full alcohol use disorders identification test in national heart, lung, and blood institute acute respiratory distress syndrome network clinical trials. Crit Care Med. 2015:43:e382-5.

12. Gacouin A, Legay F, Camus C, Volatron AC, Barbarot N, Donnio PY, Thomas $\mathrm{R}$, Le Tulzo Y. At-risk drinkers are at higher risk to acquire a bacterial infection during an intensive care unit stay than abstinent or moderate drinkers. Crit Care Med. 2008;36:1735-41.

13. Chavez LJ, Liu CF, Tefft N, Hebert PL, Clark BJ, Rubinsky AD, Lapham GT, Bradley KA. Unhealthy alcohol use in older adults: association with readmissions and emergency department use in the 30 days after hospital discharge. Drug Alcohol Depend. 2016;158:94-101.

14. Clark BJ, Rubinsky AD, Ho PM, Au DH, Chavez L, Moss M, Bradley KA. Alcohol screening scores and the risk of intensive care unit admission and hospital readmission. Subst Abus. 2016;37:466-73.

15. Jencks SF, Williams MV, Coleman EA. Rehospitalizations among patients in the Medicare fee-for-service program. N Engl J Med. 2009;360:1418-28.

16. Kripalani S, Theobald CN, Anctil B, Vasilevskis EE. Reducing hospital read mission rates: current strategies and future directions. Annu Rev Med. 2014;65:471-85.

17. Hansen LO, Young RS, Hinami K, Leung A, Williams MV. Interventions to reduce 30-day rehospitalization: a systematic review. Ann Intern Med. 2011;155:520-8.

18. Leppin AL, Gionfriddo MR, Kessler M, Brito JP, Mair FS, Gallacher K, Wang Z, Erwin PJ, Sylvester T, Boehmer K, et al. Preventing 30-day hospital readmissions: a systematic review and meta-analysis of randomized trials. JAMA Intern Med. 2014;174:1095-107.

19. Rennke S, Nguyen OK, Shoeb MH, Magan Y, Wachter RM, Ranji SR. Hospital-initiated transitional care interventions as a patient safety strategy: a systematic review. Ann Intern Med. 2013;158:433-40.

20. Jackson C, Shahsahebi M, Wedlake T, DuBard CA. Timeliness of outpatient follow-up: an evidence-based approach for planning after hospital discharge. Ann Fam Med. 2015;13:115-22.
21. Misky GJ, Wald HL, Coleman EA. Post-hospitalization transitions: examining the effects of timing of primary care provider follow-up. J Hosp Med. 2010:5:392-7.

22. Sharma G, Kuo YF, Freeman JL, Zhang DD, Goodwin JS. Outpatient follow-up visit and 30-day emergency department visit and readmission in patients hospitalized for chronic obstructive pulmonary disease. Arch Intern Med. 2010;170:1664-70.

23. Ford JD, Trestman RL, Tennen H, Allen S. Relationship of anxiety, depression and alcohol use disorders to persistent high utilization and potentially problematic under-utilization of primary medical care. Soc Sci Med. 2005;61:1618-25.

24. Hunkeler EM, Hung YY, Rice DP, Weisner C, Hu T. Alcohol consumption patterns and health care costs in an HMO. Drug Alcohol Depend. 2001;64:181-90.

25. Merrick ES, Hodgkin D, Garnick DW, Horgan CM, Panas L, Ryan M, Blow FC, Saitz R. Older adults' inpatient and emergency department utilization for ambulatory-care-sensitive conditions: relationship with alcohol consumption. J Aging Health. 2011;23:86-111.

26. Chew RB, Bryson CL, Au DH, Maciejewski ML, Bradley KA. Are smoking and alcohol misuse associated with subsequent hospitalizations for ambulatory care sensitive conditions? J Behav Health Serv Res. 2011;38:3-15.

27. Arozullah AM, Lee SY, Khan T, Kurup S, Ryan J, Bonner M, Soltysik R, Yarnold PR. The roles of low literacy and social support in predicting the preventability of hospital admission. J Gen Intern Med. 2006;21:140-5.

28. Li Y, Glance LG, Cai X, Mukamel DB. Mental illness and hospitalization for ambulatory care sensitive medical conditions. Med Care. 2008:46:1249-56.

29. Bienvenu OJ, Gerstenblith TA. Posttraumatic stress disorder phenomena after critical illness. Crit Care Clin. 2017;33:649-58.

30. Davydow DS, Gifford JM, Desai SV, Bienvenu OJ, Needham DM. Depression in general intensive care unit survivors: a systematic review. Intensive Care Med. 2009:35:796-809.

31. Davydow DS, Gifford JM, Desai SV, Needham DM, Bienvenu OJ. Posttraumatic stress disorder in general intensive care unit survivors: a systematic review. Gen Hosp Psychiatry. 2008;30:421-34.

32. Nikayin S, Rabiee A, Hashem MD, Huang M, Bienvenu OJ, Turnbull AE, Needham DM. Anxiety symptoms in survivors of critical illness: a systematic review and meta-analysis. Gen Hosp Psychiatry. 2016;43:23-9.

33. Herridge MS, Cheung AM, Tansey CM, Matte-Martyn A, Diaz-Granados N, Al-Saidi F, Cooper AB, Guest CB, Mazer CD, Mehta S, et al. One-year outcomes in survivors of the acute respiratory distress syndrome. N Engl J Med. 2003;348:683-93.

34. Lone NI, Gillies MA, Haddow C, Dobbie R, Rowan KM, Wild SH, Murray GD, Walsh TS. Five-year mortality and hospital costs associated with surviving intensive care. Am J Respir Crit Care Med. 2016;194:198-208.

35. van Walraven C, Wong J, Forster AJ. LACE + index: extension of a validated index to predict early death or urgent readmission after hospital discharge using administrative data. Open Med. 2012;6:e80-90.

36. Garrison GM, Robelia PM, Pecina JL, Dawson NL. Comparing performance of 30-day readmission risk classifiers among hospitalized primary care patients. J Eval Clin Pract. 2017;23:524-9.

37. Kleinbaum DG, Kleinbaum DG. Applied regression analysis and other multivariable methods. 4th ed. Belmont: Brooks/Cole; 2007.

38. Kim HM, Smith EG, Stano CM, Ganoczy D, Zivin K, Walters H, Valenstein M. Validation of key behaviourally based mental health diagnoses in administrative data: suicide attempt, alcohol abuse, illicit drug abuse and tobacco use. BMC Health Serv Res. 2012;12:18.

39. Williams R, Vinson DC. Validation of a single screening question for problem drinking. J Fam Pract. 2001;50:307-12.

40. Groenwold RH, Klungel OH, Grobbee DE, Hoes AW. Selection of confounding variables should not be based on observed associations with exposure. Eur J Epidemiol. 2011;26:589-93.

41. Deyo RA, Cherkin DC, Ciol MA. Adapting a clinical comorbidity index for use with ICD-9-CM administrative databases. J Clin Epidemiol. 1992;45:613-9.

42. Saitz R, Freedner N, Palfai TP, Horton NJ, Samet JH. The severity of unhealthy alcohol use in hospitalized medical patients. The spectrum is narrow. J Gen Intern Med. 2006;21:381-5.

43. Gacouin A, Tadie JM, Uhel F, Sauvadet E, Fillatre P, Letheulle J, Bouju P, Le Tulzo Y. At-risk drinking is independently associated with ICU and 
one-year mortality in critically ill nontrauma patients*. Crit Care Med. 2014:42:860-7.

44. Cryer PC, Jenkins LM, Cook AC, Ditchburn JS, Harris CK, Davis AR, Peters TJ. The use of acute and preventative medical services by a general population: relationship to alcohol consumption. Addiction. 1999;94:1523-32.

45. Green CA, Polen MR, Leo MC, Janoff SL, Anderson BM, Weisner CM, Perrin NA. Drinking patterns, gender and health III: avoiding vs. seeking healthcare. Addict Res Theory. 2010;18:160-80.

46. Anton RF, O'Malley SS, Ciraulo DA, Cisler RA, Couper D, Donovan DM, Gastfriend DR, Hosking JD, Johnson BA, LoCastro JS, et al. Combined pharmacotherapies and behavioral interventions for alcohol dependence: the COMBINE study: a randomized controlled trial. JAMA. 2006;295:2003-17.

47. Saitz R, Cheng DM, Winter M, Kim TW, Meli SM, Allensworth-Davies D, Lloyd-Travaglini CA, Samet JH. Chronic care management for dependence on alcohol and other drugs: the AHEAD randomized trial. JAMA. 2013;310:1156-67.

48. Watkins KE, Ober AJ, Lamp K, Lind M, Setodji C, Osilla KC, Hunter SB, McCullough CM, Becker K, lyiewuare PO, et al. Collaborative care for opioid and alcohol use disorders in primary care: the SUMMIT randomized clinical trial. JAMA Intern Med. 2017;177:1480-8.

49. Jonas DE, Garbutt JC, Amick HR, Brown JM, Brownley KA, Council CL, Viera AJ, Wilkins TM, Schwartz CJ, Richmond EM, et al. Behavioral counseling after screening for alcohol misuse in primary care: a systematic review and meta-analysis for the U.S. Preventive Services Task Force. Ann Intern Med. 2012;157:645-54.
50. Bryson CL, Au DH, Sun HL, Williams EC, Kivlahan DR, Bradley KA. Alcohol screening scores and medication nonadherence. Ann Intern Med. 2008; 149:795-804

51. Clark BJ, Jones J, Reed KD, Hodapp R, Douglas IS, Van Pelt D, Burnham EL, Moss $M$. The experience of patients with alcohol misuse after surviving a critical illness. A qualitative study. Ann Am Thorac Soc. 2017;14:1154-61.

52. Coleman EA, Parry C, Chalmers S, Min SJ. The care transitions intervention: results of a randomized controlled trial. Arch Intern Med. 2006;166:1822-8.

53. Voss R, Gardner R, Baier R, Butterfield K, Lehrman S, Gravenstein S. The care transitions intervention: translating from efficacy to effectiveness. Arch Intern Med. 2011;171:1232-7.

54. Chutuape MA, Katz EC, Stitzer ML. Methods for enhancing transition of substance dependent patients from inpatient to outpatient treatment. Drug Alcohol Depend. 2001;61:137-43.

55. Lash SJ. Increasing participation in substance abuse aftercare treatment. Am J Drug Alcohol Abuse. 1998;24:31-6.

56. Verinis JS, Taylor J. Increasing alcoholic patients' aftercare attendance. Int J Addict. 1994;29:1487-94.

57. Chafetz ME, Blane HT, Abram HS, Golner J, Lacy E, Mc CW, Clark E, Meyers W. Establishing treatment relations with alcoholics. J Nerv Ment Dis. 1962;134:395-409.

58. Clark BJ, Keniston A, Douglas IS, Beresford T, Macht M, Williams A, Jones J, Burnham EL, Moss M. Healthcare utilization in medical intensive care unit survivors with alcohol withdrawal. Alcohol Clin Exp Res. 2013;37:1536-43.
Ready to submit your research? Choose BMC and benefit from:

- fast, convenient online submission

- thorough peer review by experienced researchers in your field

- rapid publication on acceptance

- support for research data, including large and complex data types

- gold Open Access which fosters wider collaboration and increased citations

- maximum visibility for your research: over 100M website views per year

At BMC, research is always in progress.

Learn more biomedcentral.com/submissions 